Pacific Journal of Mathematics

BOUNDS FOR DERIVATIVES IN ELLIPTIC BOUNDARY VALUE 


\title{
BOUNDS FOR DERIVATIVES IN ELLIPTIC BOUNDARY VALUE PROBLEMS
}

\author{
J. H. Bramble and L. E. Payne
}

I. Introduction. In a recent paper [7], Payne and Weinberger gave pointwise bounds for solutions of second order uniformly elliptic partial differential equations. The bounds for the function and its gradiant involved derivatives of the boundary data. Later [2] the present authors gave a method for obtaining bounds in which no derivatives of the boundary data appeared. Pointwise bounds for derivatives were not dealt with. In [4] the authors gave a method for bounding derivatives for Poisson's equation. The method was, however, restricted to the Laplace operator (or the constant coefficient case) and was not generally applicable.

In this paper we consider the operator

$$
L u \equiv\left(a^{i j} u_{, i}\right)_{, j}
$$

where $u$ is a sufficiently smooth function defined in some region $R$ (with boundary C) of Euclidean $N$ dimensional space. Here the notation $u_{, i}$ denotes the partial derivative of $u$ with respect to the cartesian coordinate $x^{i}$. In (1.1) the summation convention is used, i.e. $\left(a^{i j} u_{, i}\right)_{, j} \equiv$ $\sum_{i j=1}^{N}\left(a^{i j} u_{, i}\right)_{, j}$. The coefficient matrix $a^{i j}$ may be a function of position and is assumed to be uniformly positive definite and bounded above. That is there exist positive constant $a_{0}$ and $a_{1}$ such that

$$
a_{0} \sum_{i=1}^{N} \xi_{i} \leqq a^{i j} \xi_{i} \xi_{j} \leqq a_{1} \sum_{i=1}^{N} \xi_{i}^{2}
$$

for any real vector $\xi=\left(\xi_{1}, \cdots, \xi_{N}\right)$. We shall give a method involving the use of a parametrix, for obtaining bounds on any derivative of a function $u$ at an arbitrary interior point $P$ of $R$. These bounds are in terms of $L u$ and $\max _{S(P)}|u|$, where $S(P)$ is a sphere containing $P$. Estimates of this type for very general elliptic operators are described by John [6]. His method does not involve the parametrix and hence the expressions which could be derived would turn out to be quite different. Thus the problem is reduced to that of bounding $\max _{S(P)}|u|$ in terms of quantities which are data of some boundary value problem. We assume throughout that $L u$ and the coefficients $a^{i j}$ are sufficiently smooth so that all subsequent indicated operations are valid.

In this paper we concern ourselves only with the derivation of appropriate a priori inequalities. The manner of applying such ine-

Received September 18, 1963. This research was supported in part by the National Science Foundation under grant-NSF GP-3. 
qualitites to obtain bounds has been thoroughly discussed in previous papers (see e.g. $[2,4,7]$ ).

II. Mean value expressions. To obtain the desired bounds we shall first need a certain expression which is in a sense analogous to the solid mean value theorem for harmonic function. One such expression was given in [2]; however, it is quite complicated. We derive now a simpler expression.

Since a fundamental solution corresponding to the operator $L$ is not in general known we make use of a Levi function (or parametrix) (c.f. Miranda [6]).

Let $P$ and $Q$ be two points in $R$. One possible definition of a parametrix is

$$
\begin{aligned}
& \Gamma(P, Q)=-(2 \pi)^{-1}[a(Q) a(P)]^{1 / 4} \log \rho, \quad N=2 \\
& \Gamma(P, Q)=2^{1 / 2(N-2)}\left[(N-2) \omega_{N}\right]^{-1}[a(Q) a(P)]^{1 / 4} \rho^{-(N-2)}, \quad N \geqq 3
\end{aligned}
$$

where $\omega_{N}$ denotes the surface of the unit sphere in $N$ dimensions,

$$
\rho^{2}=\left[a_{i j}(Q)+a_{i j}(P)\right]\left(x_{P}^{i}-x_{Q}^{i}\right)\left(x_{P}^{j}-x_{Q}^{j}\right),
$$

and $a(Q)$ denotes the determinant of the matrix $a_{i j}(Q)$, the inverse of $a^{i j}(Q)$. If the $a^{i j}$ are twice continuously differentiable in the neighborhood of $P$, this function $\Gamma$ has the property that

$$
L_{Q} \Gamma=O\left(r_{P Q}^{-(N-2)}\right), r_{P Q} \rightarrow 0
$$

where $r_{P Q}$ is the distance from $P$ to $Q$. An alternate form for a parametrix is

$$
\begin{aligned}
& \bar{\Gamma}(P, Q)=(2 \pi)^{-1}[a(P)]^{1 / 2} \log \bar{\rho} \\
& \bar{\Gamma}(P, Q)=\left[(N-2) \omega_{N}\right]^{-1}[a(P)]^{1 / 2}[\bar{\rho}]^{-(N-2)} .
\end{aligned}
$$

Here $\bar{\rho}^{2}=a_{i j}(P)\left(x_{P}^{i}-x_{Q}^{i}\right)\left(x_{P}^{j}-x_{Q}^{j}\right)$. The function $\bar{\Gamma}(P, Q)$ is such that if the $a^{i j}$ are continuously differentiable in the neighborhood of $P$, then

$$
L_{Q} \bar{\Gamma}=O\left(r_{P Q}^{-(N-1)}\right), r_{P Q} \rightarrow 0 .
$$

Comparing (2.2) and (2.4) we see that $\Gamma$ is a better approximation to the fundamental solution than is $\bar{\Gamma}$ near $Q=P$.

Now let $S_{a}(P)$ be the interior of a sphere of radius $a$ with center at $P$, and such that $S_{a}(P) \subset R$. We define the function $f_{n}(P, Q)$ as follows (for $P$ fixed)

$$
\begin{aligned}
& \text { (a) } f_{n}(P, Q)=\left\{\begin{array}{l}
1, Q=P \\
0, r_{P Q} \geqq a
\end{array}\right. \\
& \text { (b) } f_{n}^{(i)}(P, P)=0, i=1,2, \cdots, N-1 \\
& \text { (c) } f_{n}(P, Q) \in C^{n-1}\left(E^{N}\right)
\end{aligned}
$$


(continuous derivatives up to and including those of order $n-1$ at each point of Euclidean $N$-space.) One such function, for example, is the polynomial with values

$$
\left[\int_{r_{P Q}}^{a} \rho^{n-1}\left(a^{2}-\rho^{2}\right)^{n-1} d \rho\right]\left[\int_{0}^{a} \rho^{n-1}\left(a^{2}-\rho^{2}\right)^{n-1} d \rho\right]^{-1}, r_{P Q} \leqq a .
$$

Another possible choice is the function

$$
\left\{\int_{r_{P Q}}^{a} \exp \left[-\rho^{-2}\left(a^{2}-\rho^{2}\right)^{-1}\right] d \rho\right\}\left\{\int_{0}^{a} \exp \left[-\rho^{-2}\left(a^{2}-\rho^{2}\right)^{-1}\right] d \rho\right\}^{-1}, r_{P Q} \leqq a
$$

which satisfies (2.5) for all $n$. Clearly

$$
\Gamma_{n}(P, Q) \equiv f_{n}(P, Q) \Gamma(P, Q)
$$

also satisfies (2.2). But $\Gamma_{n}(P, Q)$ has all derivatives up to and including those of order $n-1$ vanishing on $r_{P Q}=a$. Using (2.1) and (2.2) we find from Green's identity that

$$
u(P)=\int_{S_{a(P)}} u(Q) L_{Q} \Gamma_{n}(P, Q) d V_{Q}-\int_{S_{S(P)}} \Gamma_{n}(P, Q) L u(Q) d V_{Q},
$$

provided $n \geqq 2$. This expression is analogous to (5.8) of [2]. In addition to being simpler it possesses the advantage that the integration is taken over spheres, rather than ellipsoids which vary from point to point. We could as well have defined

$$
\bar{\Gamma}_{n}(P, Q)=f_{n}(P, Q) \bar{\Gamma}(P, Q)
$$

and obtained

$$
u(P)=\int_{S_{a}(P)} u(Q) L_{Q} \bar{\Gamma}_{n}(P, Q) d V_{Q}-\int_{S_{a}(P)} \bar{\Gamma}_{n}(P, Q) L u(Q) d V_{Q},
$$

with $n \geqq 2$.

III. Pointwise bounds. Either (2.7) or (2.9) can be used to obtain bounds in the Dirichlet problem. Using the Schwarz inequality we have

$$
\left[\int_{S_{a}(P)} u(Q) L_{Q} \bar{\Gamma}_{n}(P, Q) d V_{Q}\right]^{2} \leqq\left[\int_{R} u^{2} r_{P Q}^{-q} d V\right]^{2}\left[\int_{S_{a}(P)} r_{P Q}^{q}\left(L \bar{\Gamma}_{n}\right)^{2} d V_{Q}\right]^{2}
$$

Equation (2.9) together with (3.1) and the bounds given by Theorem I and II of [2], yield pointwise bounds for $u$ in terms of $L u$ in $R$ and the values of $u$ on $C$.

In order to bound the first derivatives of $u$ we can use (2.7), with $n \geqq 3$, to obtain 


$$
\begin{aligned}
\frac{\partial u(P)}{\partial x_{P}^{i}}= & \int_{S_{a}(P)} u(Q) L_{Q} \frac{\partial \Gamma_{n}(P, Q)}{\partial x_{P}^{i}} d V_{Q} \\
& -\frac{\partial}{\partial x_{P}^{i}}\left[\int_{S_{a}(P)} \Gamma_{n}(P, Q) L u(Q) d V_{Q}\right] .
\end{aligned}
$$

Hence we have

$$
\begin{aligned}
\left|\frac{\partial u(P)}{\partial x_{P}^{i}}\right| \leqq & \max _{Q \in S_{a}(P)}|u(Q)| \int_{S_{a^{(P)}}}\left|L_{Q} \frac{\partial \Gamma_{n}(P, Q)}{\partial x_{P}^{i}}\right| d V_{Q} \\
& +\left|\frac{\partial}{\partial x_{P}^{i}}\left[\int_{S_{a^{(}(P)}} \Gamma_{n}(P, Q) L u(Q) d V_{Q}\right]\right| .
\end{aligned}
$$

Now if $a$ is so chosen that we can obtain a bound for $\max _{Q \in S_{a}(P)}|u(Q)|$ then (3.3) provides a bound for $\left|\partial u(P) / \partial x_{P}^{i}\right|$. If, for example, the least distance from $P$ to the boundary $C$ is $r_{0}$, then we could choose $a=$ $(1 / 2) r_{0}$. Thus the closure $\overline{S_{a}(P)}$ of $S_{a}(P)$ is a compact subset of $R$ and hence only interior bounds for $u$ are required. Note that we could not replace (3.2) by a similar expression involving $\bar{\Gamma}_{n}$ since the integrals on the right would not exist.

We note from (3.2) that

$$
\int_{S_{a}(P)} L_{Q} \frac{\partial \Gamma_{n}(P, Q)}{\partial x_{P}^{i}} d V_{Q}=0
$$

Thus if $n \geqq 4$ we have the representation

$$
\begin{aligned}
\frac{\partial^{2} u(P)}{\partial x_{P}^{i} \partial x_{P}^{j}}= & \int_{S_{a}(P)}[u(Q)-u(P)] L_{Q} \frac{\partial^{2} \Gamma_{n}(P, Q)}{\partial x_{P}^{i} \partial x_{P}^{j}} d V_{Q} \\
& -\frac{\partial^{2}}{\partial x_{P}^{i} \partial x_{P}^{j}}\left[\int_{S_{a}(P)} \Gamma_{n}(P, Q) L u(Q) d V_{Q}\right]
\end{aligned}
$$

since

$$
[u(Q)-u(P)] L_{Q} \frac{\partial^{2} \Gamma_{n}(P, Q)}{\partial x_{P}^{i} \partial x_{P}^{j}}=O\left(r_{P Q}^{-(N-1)}\right)
$$

for $r_{P Q} \rightarrow 0$. From (3.5) we see that

$$
\begin{aligned}
\left|\frac{\partial^{2} u(P)}{\partial x_{P}^{i} \partial x_{P}^{j}}\right| \leqq & \max _{Q \in S_{a}(P)}\left|\frac{u(Q)-u(P)}{r_{P Q}}\right| \int_{S_{a}(P)} r_{P Q}\left|L_{Q} \frac{\partial^{2} \Gamma_{n}(P, Q)}{\partial x_{P}^{i} \partial x_{Q}^{j}}\right| d V_{Q} \\
& +\left|\frac{\partial^{2}}{\partial x_{P}^{i} \partial x_{P}^{j}}\left[\int_{S_{a}(P)} \Gamma_{n}(P, Q) L u(Q) d V_{Q}\right]\right| .
\end{aligned}
$$

Now

$$
\max _{Q \in S_{\alpha}(P)}\left|\frac{u(Q)-u(P)}{r_{P Q}}\right| \leqq \max _{Q \in S_{S}(P)}|\operatorname{grad} u(Q)|
$$


Clearly we can use (3.3) with a smaller value of $a$ to bound the right hand side of (3.8). Thus we can bound an arbitrary second derivative of $u$ in terms of $L \mathrm{u}$ in $R$ and the maximum of $|u|$ over a compact subset of $R$. In order to treat an arbitrary third derivative we note from (3.5) that

$$
\int_{S_{a}(P)}\left(x_{Q}^{\alpha}-x_{P}^{\alpha}\right) L_{Q} \frac{\partial^{2} \Gamma_{n}(P, Q)}{\partial x_{P}^{i} \partial x_{P}^{j}} d V_{Q}=\frac{\partial^{2}}{\partial x_{P}^{i} \partial x_{P}^{j}}\left[\int_{S_{a}(P)} \Gamma_{n}(P, Q) L x_{Q}^{\alpha} d V_{Q}\right]
$$

for $\alpha, i, j=1, \cdots, N$. Combining (3.9) and (3.5) we have

$$
\begin{aligned}
\frac{\partial^{2} u(P)}{\partial x_{P}^{i} \partial x_{P}^{j}}= & \int_{s_{a}(P)}\left[u(Q)-u(P)-\left(x_{Q}^{\omega}-x_{P}\right) u_{, \alpha}(P)\right] L_{Q} \frac{\partial^{2} \Gamma_{n}(P, Q)}{\partial x_{P}^{i} \partial x_{P}^{j}} d V_{Q} \\
& -\frac{\partial^{2}}{\partial x_{P}^{i} \partial x_{P}^{j}}\left[\int_{S_{a}(P)} \Gamma_{n}(P, Q) L u(Q) d V_{Q}\right] \\
& -u_{, a}(P) \frac{\partial^{2}}{\partial x_{P}^{i} \partial x_{P}^{j}}\left[\int_{S_{a}(P)} \Gamma_{n}(P, Q) L x_{Q}^{a} d V_{Q}\right]
\end{aligned}
$$

where we have summed over $\alpha$ from 1 to $N$. It follows from (3.10) that if $n \geqq 5$

$$
\begin{aligned}
\frac{\partial^{3} u(P)}{\partial x_{P}^{i} \partial x_{P}^{j} \partial x_{P}^{k}}= & \int_{S_{a}(P)}\left[u(Q)-u(P)-\left(x_{Q}^{\alpha}-x_{P}^{\alpha}\right) u, \alpha(P)\right] L_{Q} \frac{\partial^{3} \Gamma_{n}(P, Q)}{\partial x_{P}^{i} \partial x_{P}^{j} \partial x_{P}^{k}} d V_{Q} \\
& -\frac{\partial^{3}}{\partial x_{P}^{i} \partial x_{P}^{j} \partial x_{P}^{k}}\left[\int_{S_{a}(P)} \Gamma_{n}(P, Q) L u(Q) d V_{Q}\right] \\
& -u_{, \alpha}(P) \frac{\partial^{3}}{\partial x_{P}^{i} \partial x_{P}^{j} \partial x_{P}^{k}}\left[\int_{S_{a}(P)} \Gamma_{n}(P, Q) L x_{Q}^{\alpha} d V_{Q}\right] .
\end{aligned}
$$

The first integral on the right may be bounded as

$$
\begin{aligned}
& \left|\int_{S_{a}(P)}\left[u(Q)-u(P)-\left(x_{Q}^{\alpha}-x_{P}^{\alpha}\right) u_{, \alpha}(P)\right] L_{Q} \frac{\partial^{3} \Gamma_{n}(P, Q)}{\partial x_{P}^{i} \partial x_{P}^{j} \partial x_{P}^{k}} d V_{Q}\right| \\
& \quad \leqq \max _{\substack{Q \in S a(P) \\
\alpha \in=1}}\left|u_{, \alpha \beta}(Q)\right| \int_{S_{a}(P)} r_{P Q}^{2}\left|L_{Q} \frac{\partial^{3} \Gamma_{n}(P, Q)}{\partial x_{P}^{i} \partial x_{P}^{j} \partial x_{P}^{k}}\right| d V_{Q} .
\end{aligned}
$$

Now (3.11) and (3.12) can be used to reduce the problem of bounding third derivatives to that of bounding second derivatives. It is clear how to proceed to higher derivatives. In each of the preceding bounds certain differentiability assumptions must be made. These conditions become more and more stringent the more derivatives of $u$ that we wish to bound. Some conditions of this nature are of course required since in general $u$ cannot be expected to be smooth.

Thus for an arbitrary derivative at $P$ the method described above yields a bound in terms of $L u$ in $R$ and the maximum of $|u|$ on a compact subset (for example $S_{a}(P)$ for some $a$ ) of $R$. These bounds, together with bounds for $|u|$ in $S_{a}(P)$ in terms of data in various 
boundary value problems, yield pointwise bounds for derivatives at interior points in terms of the respective data. For such bounds see $[1,2,3,4,5,7,8]$.

The techniques which we have used here to bound derivatives of solutions to boundary value problems at interior points in terms of the operator and bounds for the solution itself, will carry over quite naturally to higher order equations and to equations of other than elliptic type.

\section{BIBLIOGRAPHY}

1. F. J. Bellar, Pointwise bounds in parabolic and elliptic partial differential equations, $\mathrm{Ph}$. D. dissertation, University of Maryland (1961).

2. J. H. Bramble, L. E. Payne, Bounds for solutions of second order elliptic partial differential equations, Contributions to Differential Equations, Vol. I, (1963), 95-127.

3. - Some integral inequalities for uniformly elliptic operators, Contributions to Differential Equations, Vol. I, (1963), 129-135.

4. - Bounds for derivatives in the Dirichlet problem for Poisson's equation, J. Soc. Ind. Appl. Math., 10 (1962), 370-380.

5. — Bounds in the Neumann problem for second order uniformly elliptic operators, Pacific J. Math., 12 (1962), 823-833.

6. C. Miranda, Equazioni alle derivate parziali di tipo ellitico, Springer-Verlag, Berlin (1955).

7. L. E. Payne, H. F. Weinberger, New bounds for solutions of second order elliptic partial differential equations, Pacific J. Math., 8 (1958), 551.

8. G. N. Trytten, Pointwise bounds for solutions in the Cauchy problem for elliptic equations, Arch. Rat. Mech. Anal., 13 (1963), 222.

UNIVERSITY OF MARYLAND 


\section{PACIFIC JOURNAL OF MATHEMATICS}

\section{EDITORS}

\author{
Robert Osserman \\ Stanford University \\ Stanford, California
M. G. Arsove
University of Washington
Seattle 5 , Washington

\author{
J. DugundJI \\ University of Southern California \\ Los Angeles 7, California
}

Lowell J. Paige

University of California

Los Angeles 24, California

\section{ASSOCIATE EDITORS}
E. F. BECKENBACH
B. H. NeumanN
F. WOLF
K. YOSIDA

\section{SUPPORTING INSTITUTIONS}

\author{
UNIVERSITY OF BRITISH COLUMBIA \\ CALIFORNIA INSTITUTE OF TECHNOLOGY \\ UNIVERSITY OF CALIFORNIA \\ MONTANA STATE UNIVERSITY \\ UNIVERSITY OF NEVADA \\ NEW MEXICO STATE UNIVERSITY \\ OREGON STATE UNIVERSITY \\ UNIVERSITY OF OREGON \\ OSAKA UNIVERSITY \\ UNIVERSITY OF SOUTHERN CALIFORNIA
}

\author{
STANFORD UNIVERSITY \\ UNIVERSITY OF TOKYO \\ UNIVERSITY OF UTAH \\ WASHINGTON STATE UNIVERSITY \\ UNIVERSITY OF WASHINGTON \\ * * * * \\ AMERICAN MATHEMATICAL SOCIETY \\ CALIFORNIA RESEARCH CORPORATION \\ SPACE TECHNOLOGY LABORATORIES \\ NAVAL ORDNANCE TEST STATION
}

Mathematical papers intended for publication in the Pacific Journal of Mathematics should by typewritten (double spaced), and on submission, must be accompanied by a separate author's résumé. Manuscripts may be sent to any one of the four editors. All other communications to the editors should be addressed to the managing editor, L. J. Paige at the University of California, Los Angeles 24, California.

50 reprints per author of each article are furnished free of charge; additional copies may be obtained at cost in multiples of 50 .

The Pacific Journal of Mathematics is published quarterly, in March, June, September, and December. Effective with Volume 13 the price per volume (4 numbers) is $\$ 18.00$; single issues, $\$ 5.00$. Special price for current issues to individual faculty members of supporting institutions and to individual members of the American Mathematical Society: $\$ 8.00$ per volume; single issues $\$ 2.50$. Back numbers are available.

Subscriptions, orders for back numbers, and changes of address should be sent to Pacific Journal of Mathematics, 103 Highland Boulevard, Berkeley 8, California.

Printed at Kokusai Bunken Insatsusha (International Academic Printing Co., Ltd.), No. 6, 2-chome, Fujimi-cho, Chiyoda-ku, Tokyo, Japan.

PUBLISHED BY PACIFIC JOURNAL OF MATHEMATICS, A NON-PROFIT CORPORATION

The Supporting Institutions listed above contribute to the cost of publication of this Journal, but they are not owners or publishers and have no responsibility for its content or policies. 


\section{Pacific Journal of Mathematics}

\section{Vol. 14, No. $3 \quad$ July, 1964}

Erik Balslev and Theodore William Gamelin, The essential spectrum of a class of ordinary differential operators . . . . . . . . . . . . . . . . . . . .

James Henry Bramble and Lawrence Edward Payne, Bounds for derivatives in

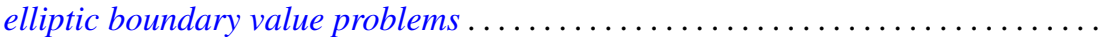

Hugh D. Brunk, Integral inequalities for functions with nondecreasing

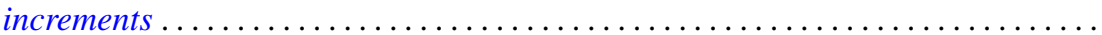

William Edward Christilles, A result concerning integral binary quadratic

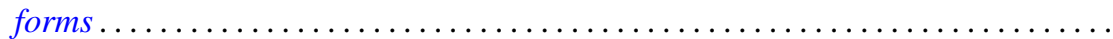

Peter Crawley and Bjarni Jónsson, Refinements for infinite direct decompositions of

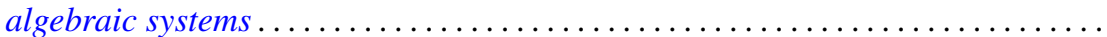

Don Deckard and Carl Mark Pearcy, On continuous matrix-valued functions on a Stonian space.

Raymond Frank Dickman, Leonard Rubin and P. M. Swingle, Another

characterization of the $n$-sphere and related results $\ldots \ldots \ldots \ldots \ldots \ldots$

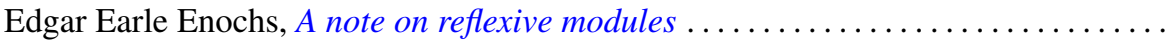

Vladimir Filippenko, On the reflection of harmonic functions and of solutions of the

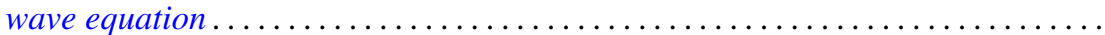

Derek Joseph Haggard Fuller, Mappings of bounded characteristic into arbitrary

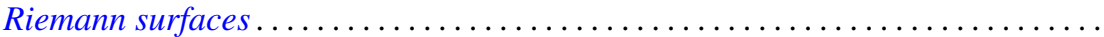
895

Curtis M. Fulton, Clifford vectors . . . . . . . . . . . . . . . . . . . . . . . . . . . . . . 917

Irving Leonard Glicksberg, Maximal algebras and a theorem of Radó . .

919

Kyong Taik Hahn, Minimum problems of Plateau type in the Bergman metric

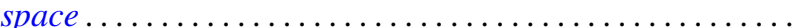

A. Hayes, A representation theory for a class of partially ordered rings...

J. M. C. Joshi, On a generalized Stieltjes trasform

J. M. C. Joshi, Inversion and representation theorems for a generalized Laplace transform ...

Eugene Kay McLachlan, Extremal elements of the convex cone $B_{n}$ of functions ...

Robert Alan Melter, Contributions to Boolean geometry of p-rings ...

James Ronald Retherford, Basic sequences and the Paley-Wiener criterion . . . . . . . 1019

Dallas W. Sasser, Quasi-positive operators. .

Oved Shisha, On the structure of infrapolynomials with prescribed coefficients ..

Oved Shisha and Gerald Thomas Cargo, On comparable means

Maurice Sion, A characterization of weak ${ }^{*}$ convergence ........

Morton Lincoln Slater and Robert James Thompson, A permanent inequality for

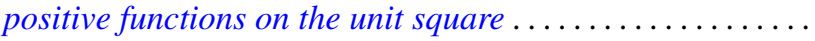

David A. Smith, On fixed points of automorphisms of classical Lie algebras ...

Sherman K. Stein, Homogeneous quasigroups ................

J. L. Walsh and Oved Shisha, On the location of the zeros of some infrapolynomials with prescribed coefficients .

Ronson Joseph Warne, Homomorphisms of $d$-simple inverse semigroups with identity . 